RAMOS, C. A. As faces da liberdade e a teoria do reconhecimento. Curitiba: PUCPRess, 2016.

\title{
Jairo Marçal*
}

Centro Universitário UniBrasil, Curitiba, PR, Brasil

Um dos grandes dilemas da modernidade se expressa no confronto agudo e contraditório que opõe, de um lado, o desejo da liberdade individual, sem interferências, e do outro lado, a necessidade humana da vida em comunidade, que se organiza por normas e leis. Esse conflito fundamental suscita questões filosóficas em torno da ideia de liberdade - a liberdade pode ser compreendida como um atributo essencialmente individual? Se, as relações intersubjetivas, sociais e políticas demandam regras, e se as regras interferem na liberdade individual, como é possível falar em liberdade nesses contextos? É possível conciliar essas dimensões aparentemente tão controversas? Essas questões têm sido equacionadas e enfrentadas por grandes pensadores de diversos matizes, sobretudo a partir do século XVIII e, permanecem francamente abertas e desafiadoras.

O livro As faces da liberdade e a teoria do reconhecimento, de Cesar Augusto Ramos, apresenta aos leitores uma discussão de grande

* JM: Mestre (UFPR) e doutorando (PUCPR) em Filosofia Política, e-mail: jairomarcal@gmail.com 
relevância sobre um dos temas mais instigantes da filosofia política contemporânea e se caracteriza pela amplitude e profundidade da pesquisa em torno da questão filosófica da liberdade, nas suas dimensões individual, social e política.

A obra não se limita a uma única perspectiva de análise, ou à leitura endógena de um autor ou de uma corrente e, tampouco opta por discorrer, de forma meramente enciclopédica, sobre as diversas correntes que disputam a melhor interpretação do tema. De forma arrojada, o texto de Ramos coloca frente a frente as múltiplas faces da liberdade e, nesse cenário promove um debate profícuo que culmina com a defesa da tese de que "a liberdade individual necessita ter uma expressão intersubjetiva e institucional para sua efetiva realização". Esse é o leitmotif do livro, que se expressa também pela força promissora do conceito hegeliano de liberdade - "estar consigo mesmo no seu outro".

Outro aspecto metodológico que se revela na tessitura do texto é o trabalho cuidadoso do autor na articulação entre os filósofos clássicos, que se dedicaram a pensar o tema da liberdade e na atualização dos seus conceitos por pensadores contemporâneos. Também merece destaque a bibliografia altamente qualificada, que coloca o leitor em contato com as discussões mais atuais sobre o tema, em âmbito internacional.

O livro é estruturado em quatro partes - a primeira parte aborda a face individual da liberdade; a segunda parte trata da face intersubjetiva da liberdade e sua dimensão social; a terceira parte apresenta a face republicana da liberdade; a última parte é dedicada ao reconhecimento na mediação das faces da liberdade.

A primeira parte do livro é dedicada à análise do conceito de liberdade como autonomia moral e pessoal, que emerge na história da filosofia pela via do liberalismo filosófico. $\mathrm{O}$ individualismo dos modernos se configura, essencialmente, pela concepção da liberdade como direito subjetivo (natural) vinculada ao indivíduo, que acaba por marcar de maneira decisiva toda a tradição do pensamento liberal clássico.

A discussão em torno da liberdade individual é apresentada por Ramos num percurso que vai do liberalismo moderado de John Stuart Mill, passando pelo perfeccionismo moral de Joseph Raz, pela distinção clássica entre liberdade negativa e liberdade positiva, estabelecida por 
Isaiah Berlin, pelas vinculações entre a liberdade negativa e os limites legais e constitucionais na teoria de John Rawls, até a ideia de autonomia estritamente pessoal das volições de segunda ordem de Harry Frankfurt.

Ramos demonstra que para Isaiah Berlin a liberdade é observável "na ausência de ações que podem criar impedimentos arbitrários e indevidos à livre atividade dos sujeitos". Para o liberalismo, a lei não pode ser tomada como elemento intrínseco à liberdade e, tampouco, na condição de sua promotora, como assevera o republicanismo, mas "é apenas um instrumento de proteção da liberdade como direito fundamental". Já a ideia de liberdade em Rawls, mesmo que discutida na relação com as limitações legais e constitucionais, permanece tal qual em Berlin, fundada no registro da liberdade negativa.

Segundo Ramos, ainda que Berlin e Rawls tenham se destacado pelas apresentações da ideia de liberdade negativa, fortemente vinculadas à defesa das escolhas individuais livres de interferências, suas concepções de liberdade individual valorizam também a liberdade positiva (autonomia pessoal), como na clássica formulação de Kant, vinculada à "autorrealização para a consecução de uma vida boa".

A concepção liberal da liberdade contribuiu para o desenvolvimento da ideia de autonomia individual, com significativo impacto na forma de vida das sociedades modernas e, subsidiou posicionamentos contrários a tiranias e várias formas de autoritarismo, mas, por outro lado, o seu caráter atomista e disjuntivo revela sua fragilidade e, a face sombria do individualismo exacerbado tem trazido consequências deletérias à vida em sociedade.

A segunda parte do livro apresenta o conceito hegeliano de liberdade e sua reatualização pelo filósofo da Teoria Crítica, Axel Honneth. Aqui, a ideia central consiste na superação do caráter disjuntivo (individualista) caracterizado nas concepções de liberdade individual negativa e positiva, constituindo assim um conceito social de liberdade, que se desenvolve pela relação do eu com o seu outro (alteridade).

A proposta de Hegel é solucionar a equação identidade $x$ alteridade, aparentemente paradoxal, pelo menos à luz da concepção liberal. Ramos argumenta que, na concepção hegeliana, essa díade não é vista como um problema, mas sim como uma possibilidade de interação e de efetivação 
da liberdade em seus momentos subjetivo e objetivo. Em outras palavras, na filosofia hegeliana, a liberdade somente se efetiva nas relações intersubjetivas e na racionalidade das instituições sociais e políticas.

Honneth assume o conceito hegeliano de liberdade e, portanto, também se volta para a tentativa de conciliação das dimensões individual e social da liberdade, sem subordinar, contudo, a liberdade do indivíduo a qualquer forma de razão ou ética estatal. Na dimensão individual da liberdade, Honneth amplia essa perspectiva considerando os aspectos psicológicos e afetivos. Essa reatualização do conceito hegeliano de liberdade, proposta por Honneth, é importante porque, na medida em que amplia o campo de abordagem, favorece o seu uso na análise das sociedades atuais.

A terceira parte do livro propõe uma abordagem mais ampla que a do individualismo liberal, a partir da conjunção das dimensões subjetiva (individual) e objetiva (institucional). Ramos observa que "o tema mais comum e influente nas diversas formas de apresentação do republicanismo foi a causa do viver livre (vivere libero) em um Estado livre" e, apresenta essa face da liberdade a partir da análise das filosofias de Jean-Jacques Rousseau, Hannah Arendt, Philip Pettit e Charles Taylor.

Rousseau define o sentido público da liberdade política ao assumir que a "interdependência entre os homens foi irrevogavelmente incorporada nas relações sociais" e que, nessa condição, a liberdade de cada um só pode ser assegurada numa ordem civil, resultado da vontade geral e mobilizada pelo exercício do direito político dos indivíduos.

Arendt, cujo pensamento tem matriz aristotélica, se inspira na polis ateniense e, na posição de crítica do individualismo e do egoísmo que marcam de forma indelével a modernidade, sustenta que a razão de ser da política é a liberdade, mas que esta só se realiza na dimensão da vida em comum, por meio da ação deliberativa.

O comunitarismo de Charles Taylor recria o indivíduo, afastando-o da perspectiva sombria e empobrecedora do egoísmo moderno, para fazê-lo emergir na condição de um individualismo expressivo, que afirma a identidade do sujeito, por meio de valores associados à comunidade.

Pettit, vinculado ao republicanismo neorromano, critica tanto o atomismo liberal, quanto as formas ortodoxas de coletivismo, buscando 
conciliar a liberdade individual e a liberdade política (individualismo holista) com base na ideia da não dominação, apoiada no consequencialismo. Para Pettit, são as leis não arbitrárias de um Estado republicano que tornam possível e asseguram a liberdade dos indivíduos. Entretanto, para que haja boas leis, que garantam autoridade aos governantes e liberdade aos cidadãos, é fundamental a cidadania ativa e o exercício da democracia contestatória, ancoradas pelo controle discursivo, que articula as dimensões psicológica (individual), social e política.

Na última parte do livro, Cesar Ramos propõe a teoria do reconhecimento como mediadora das faces da liberdade. $\mathrm{O}$ argumento central da sua análise se estrutura a partir da questão inevitável de que "a liberdade individual necessita ter uma expressão intersubjetiva e institucional para sua efetiva realização".

A teoria do reconhecimento demanda que as relações intersubjetivas, com interatividade recíproca, estejam presentes na raiz das teorias da liberdade de cunho social, cujo objetivo é a crítica e a superação das propostas que restringem a liberdade à dimensão individual e autorreferente, restrita ao âmbito normativo das teorias da justiça e ao formalismo jurídico.

A perspectiva da necessidade do reconhecimento pelo outro e, também as consequências da ausência ou mesmo da negação de tal reconhecimento, estão presentes no republicanismo neoateniense de Arendt, no comunitarismo de Taylor e no republicanismo neorromano de Pettit, mas é em Hegel e na reatualização de seu conceito de liberdade, empreendido por Honneth, que o tema assume maior clareza e profundidade, na medida em que a reconstrução normativa, proposta pelo filósofo, passa a "considerar as instituições e práticas sociais, destacando aquelas que permitem considerar a constituição da liberdade como um bem socialmente compartilhado e que possuem valor normativo". Para Honneth, a luta por reconhecimento perpassa as relações afetivas, as reinvindicações de direitos e a busca pela estima social e, a sua ausência nessas esferas deprecia as identidades individuais, implicando na luta por reconhecimento.

As faces da liberdade e a teoria do reconhecimento, de Cesar Ramos, é um trabalho filosófico estimulante, resultado de uma pesquisa acurada, 
que se destaca pelo tratamento crítico e refinado do objeto de análise e pela elegância da sua escrita. O livro se apresenta como uma importante referência na filosofia política e merece ser lido e discutido por especialistas, mas também despertará o interesse dos leitores com apreço pelo tema da liberdade.

O livro está disponível na versão impressa e a PUCPRess está providenciando também a versão eletrônica (e-book), revisada pelo autor.

Recebido: 28/06/2017

Received: 06/28/2017

Aprovado: 19/07/2017

Approved: 07/19/2017 